\title{
Extralobar lung sequestration associated with fatal neonatal respiratory distress
}

\author{
A. J. BLIEK and D. J. MULHOLLAND
}

The Departments of Radiology and Pathology, Royal Alexandra Hospital, Edmonton, Alberta

The radiological and pathological findings of lung sequestration in a premature infant are described. There was a left-sided variant of the extralobar type with double systemic arterial blood supply, single systemic venous drainage, and an incomplete bronchial tree for the remainder of the left lung.

A white female infant was born at 34 weeks' gestation by breech extraction with Piper forceps on the aftercoming head. The spontaneous labour had lasted four-and-a-half hours with rupture of the membranes at the time of delivery. Polyhydramnios was noted but not measured: the placenta was unremarkable.

The mother was a healthy 25-year-old gravida 4, para 3, whose antenatal course had been marked by nausea and vomiting throughout with spotty bleeding of short duration at three-and-ahalf months. No drugs were administered during the pregnancy other than a single tetanus injection after a foot injury. She had gained $42 \mathrm{lb}$ $(19 \mathrm{~kg})$. One live sibling had Down's syndrome.

The infant's birth weight was $6 \mathrm{lb} 3 \mathrm{oz}(2,800 \mathrm{~g})$, and her total length was 20 in $(50 \mathrm{~cm})$. At birth the infant was cyanosed, grey, and gasping with gross indrawing. After suction and intubation she was placed in a respirator, when the Apgar rating improved from 5 to 6 . In spite of vigorous treatment of the ensuing hypoxia and acidosis ( $\mathrm{pH}$ below 6.8), the infant died two hours and six minutes after birth.

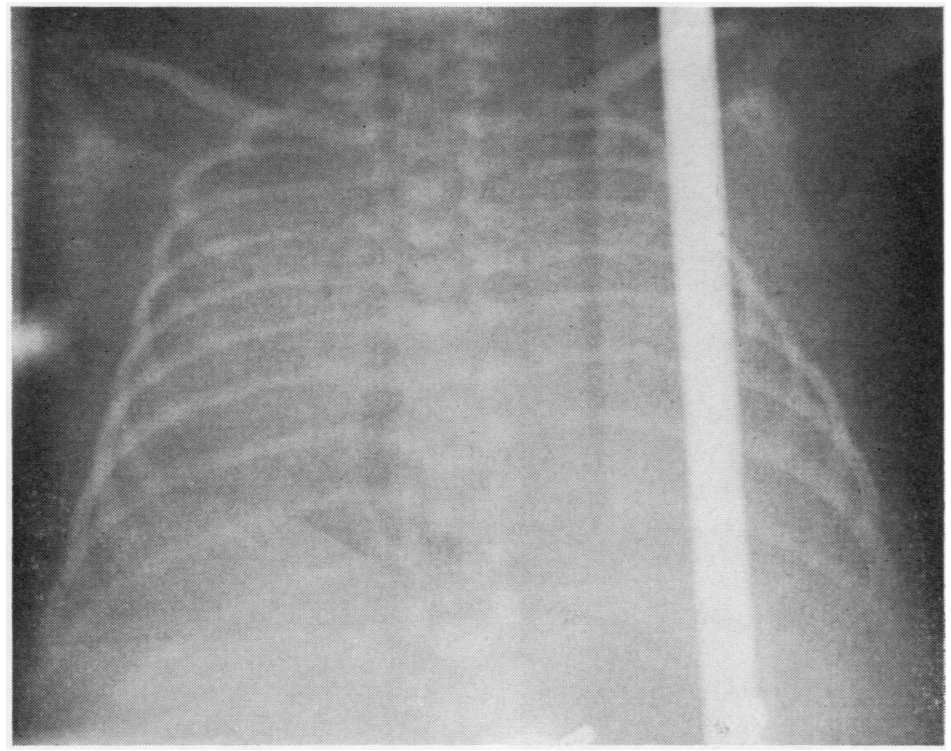

FIG. 1. Antemortem chest radiograph showing dense left hemithorax and faintly visualized trachea and right main bronchus. 
A chest radiograph (Fig. 1) showed the presence of air in the oesophagus. The right lung was densely consolidated with a well-developed airbronchogram. The left hemithorax was opaque without a recognizable air-bronchogram, suggesting occlusion or atresia of the left main-stem bronchus.

\section{NECROPSY FINDINGS}

Obvious anomalies were seen when the thorax was opened, and before evisceration a small polyethylene catheter was introduced into the aorta via the left external iliac artery. Three millilitres of $60 \%$ meglumine iothalamate were injected and radiographs were obtained. Two systemic arteries originating from the thoracic aorta were seen supplying a large mass in the left hemithorax (Fig. 2). The ductus arteriosus was patent. Subsequently $2 \mathrm{ml}$ of contrast medium were instilled into the trachea and bronchial tree and a radiograph (Fig. 3) showed a normal right but incomplete left bronchial tree. No connexion with the left intrathoracic mass was evident.

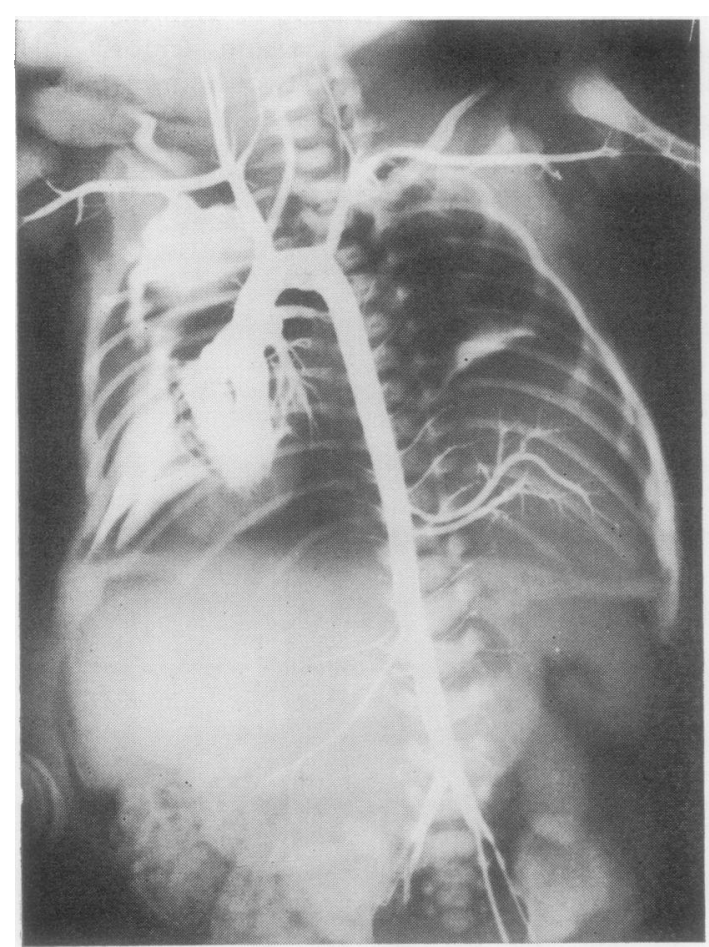

FIG. 2. Postmortem aortogram showing two arteries supplying the sequestered lung tissue.

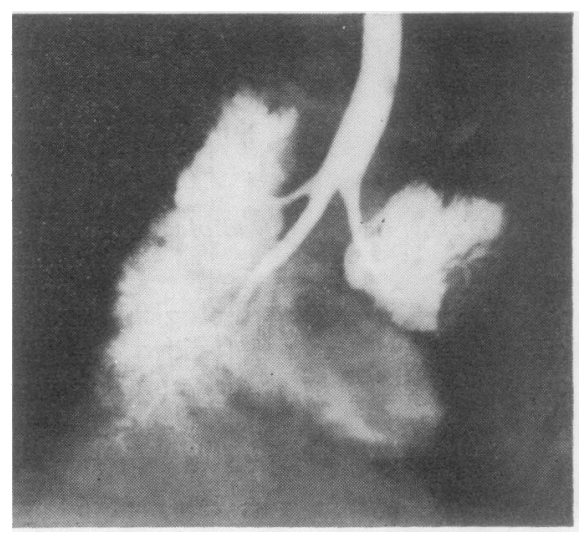

FIG. 3. A normal right but incomplete left bronchial tree are demonstrated. No connexion with the mass is evident.

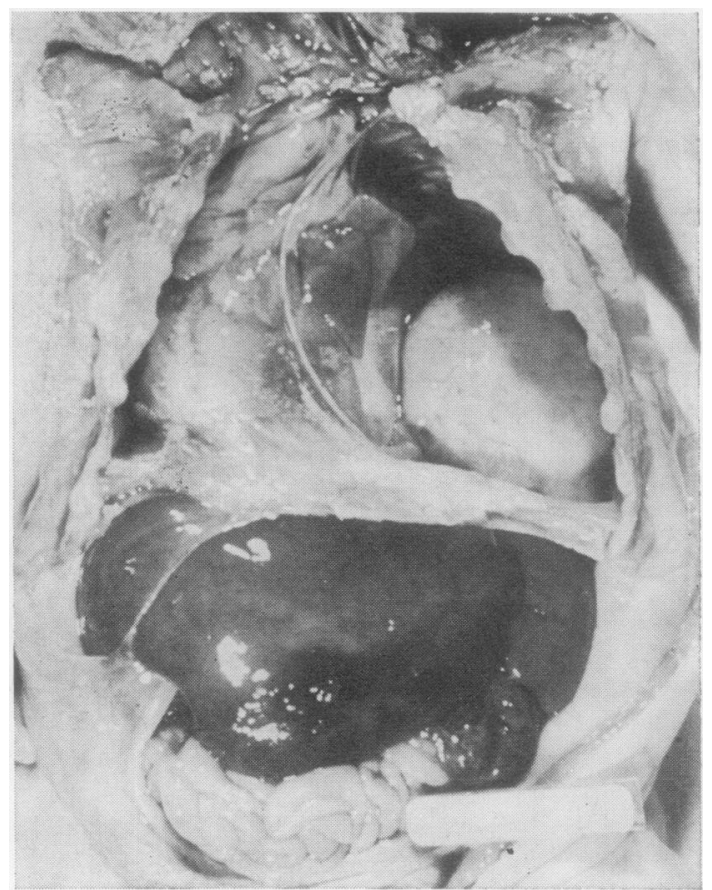

FIG. 4. In the opened thoracic cavity the mass is seen displacing the heart and mediastinum. 


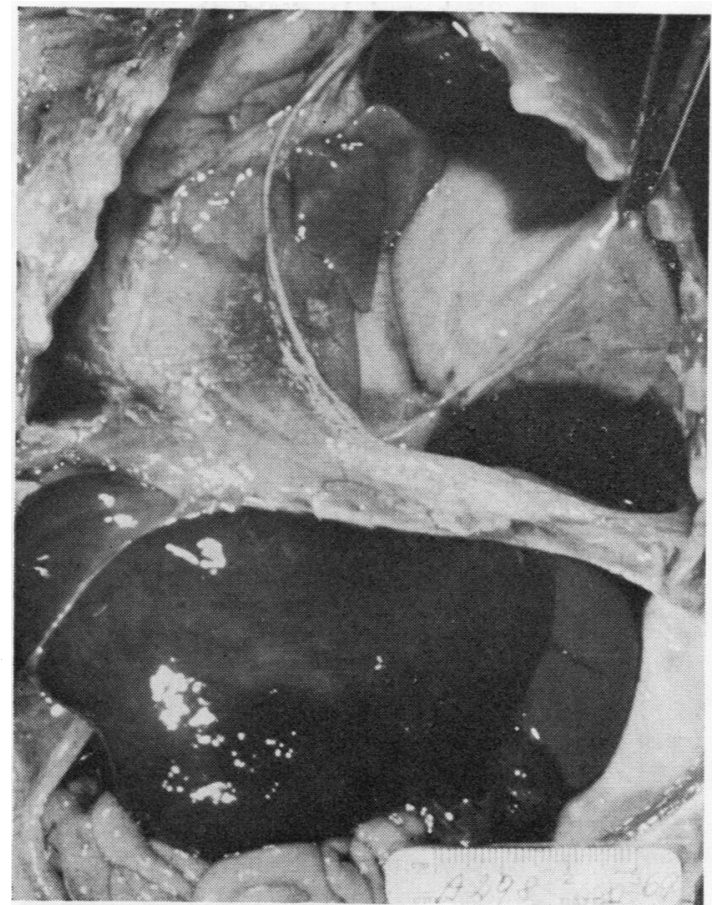

FIG. 5. The narrow pedicle connecting the mass with the pulmonary ligament contains two arteries and one vein. No diaphragmatic hernia is evident.

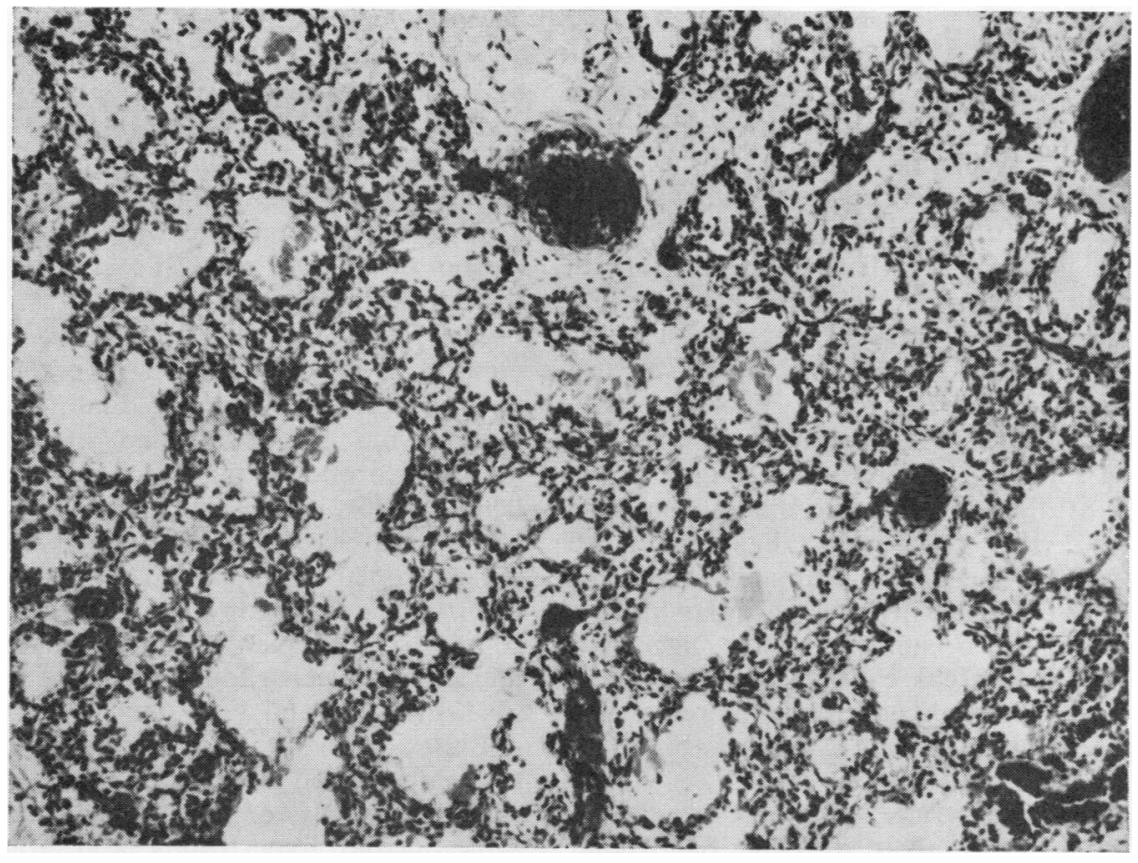

FIG. 6. The right and left lungs show a moderate degree of collapse. Alveolar development is present and patchy hyaline membrane formation is noted $(\times 125)$. 


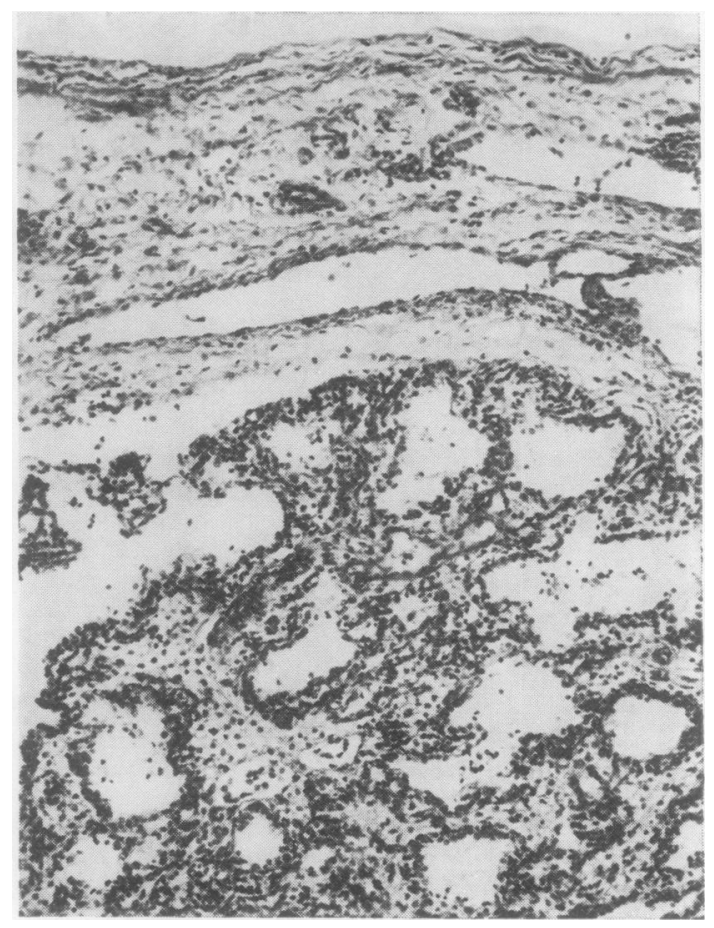

FIG. 7. The sequestrated lobe has a separate pleural covering with dilated subpleural lymphatic spaces.

In the thorax there was a left-sided pleural effusion of 20-30 ml of straw-coloured fluid and a small left lung weighing $4 \mathrm{~g}$. Most of the left pleural cavity was occupied by a smooth-surfaced, pink-grey mass of solid tissue, measuring $5 \times 3.5 \times$ $3 \mathrm{~cm}$ and weighing $35.5 \mathrm{~g}$. The mediastinal structures were shifted to the right compressing the contralateral lung (Figs 4 and 5). Two small systemic arteries located immediately above the diaphragm led directly from the aorta to the mass. A single vein provided drainage to the inferior vena cava. All three vessels passed through a small fibrous stalk at the infero-postero-medial aspect of the mass to the pulmonary ligament. The diaphragm was normal. Approximately $50 \mathrm{ml}$ of bloody fluid associated with a subcapsular haematoma on the anterior surface of the liver was found in the abdominal cavity. Except for the presence of a Meckel's diverticulum the remainder of the gross examination was unremarkable.

MICROSCOPICAL EXAMINATION Tissue sections of the right lung revealed an advancd degree of alveolar development with slightly thickened but wellvascularized alveolar septa. Patchy hyaline mem- brane formation was present with epithelial debris and fluid accumulation in some of the airspaces. An uneven degree of dilatation of the alveolar airspaces was probably due to the short period of artificial ventilation (Fig. 6).

The small left lung was similar histologically to the right lung.

The left-sided pulmonary mass had a separate pleural covering which in several areas showed 0 much subpleural lymphatic dilatation (Fig. 7). The parenchyma was composed of a multitude of $\frac{D}{0}$ 'terminal bronchiole-like' spaces lined by a single layer of low cuboidal epithelium. Only a few $\mathcal{N}$ scattered areas showed a pattern compatible with $N$ early alveolar development. The septa were thick, N poorly vascularized, and composed of a loose $\omega$ cellular stroma. Neither epithelial cells nor hyaline membranes were found within the respiratory spaces (Figs 8 and 9).

Elastic stains of the aberrant arteries supplying ? the sequestrated pulmonary tissue revealed them $\frac{0}{0}$ to be primarily of a systemic type with negli- $\underset{\mathbb{D}}{\stackrel{D}{ }}$ gible medial hypertrophy and abundant elastic $\frac{?}{\Phi}$

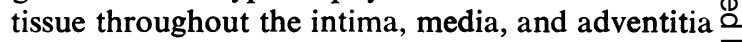
(Fig. 10). 

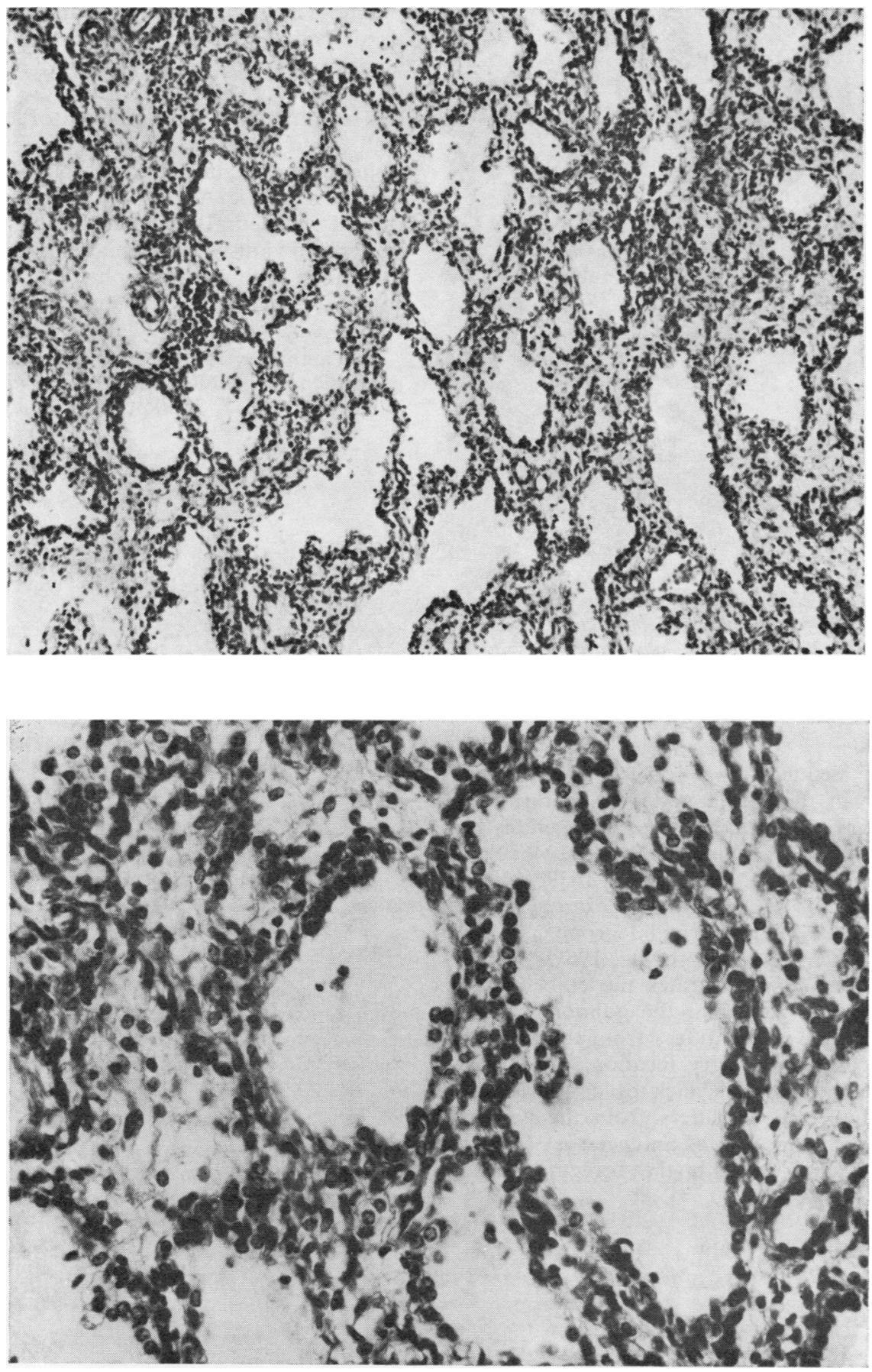

FIGS 8 and 9. The parenchyma of the sequestrated lobe is composed of 'terminal bronchiole-like' spaces with a single layer of low cuboidal epithelium. Scattered areas show early alveolar development. ( $\times 125$ and 300$)$. 


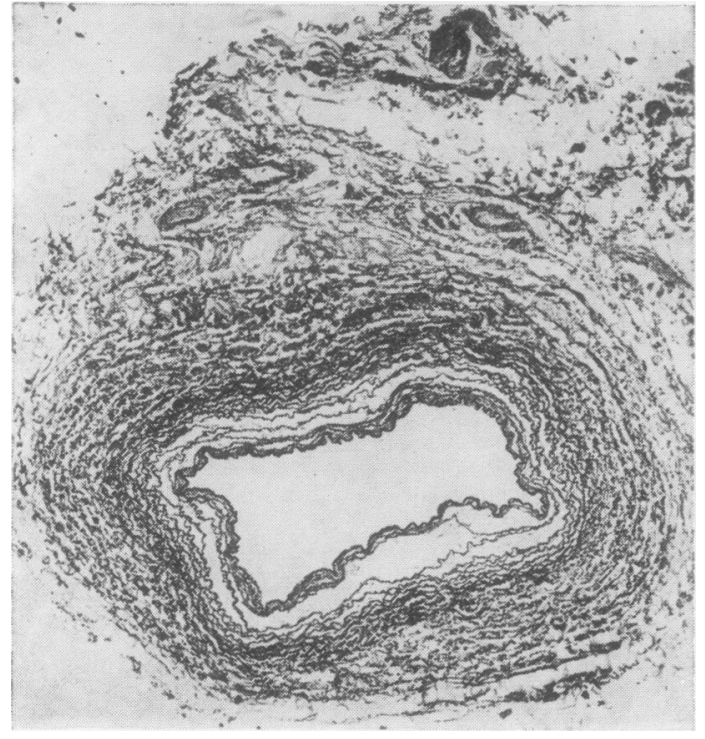

FIG. 10. Elastic stains of the aberrant arteries show minimal medial hypertrophy and abundant elastic tissue throughout the intima, media, and adventitia. ( $\times 42)$.

\section{DISCUSSION}

Pulmonary sequestration has been documented extensively in the recent and past literature and various theories regarding its embryogenesis have been presented and reviewed (Pryce, 1946; Smith, 1956; Berman, 1958; Swierenga, 1959; Nielsen, 1964; Köhler, 1969). Only a few examples of the extralobar type in the perinatal group have been reported (Potter, 1961; Horowitz, 1965).

The present case illustrates the embryogenesis of the lesion, in particular the pulmonary origin. The extralobar variant differs from the intralobar one in its extrapulmonary location, with its own pleural covering and its lack of connexion with the bronchial tree. It differs from the accessory lung due to the absence of an accessory bronchus or other connexion with the foregut (Spencer, 1962; Blesovsky, 1967).
The lack of respiratory epithelium in the mass, its systemic blood supply, and histological featureso confirm the common pattern of this lesion (Wagenvoort, Heath and Edwards, 1964; Kissanes and Smith, 1967). The spectrum of anomalies may well justify the name of congenital bronchos pulmonary-foregut malformation, as suggested byGerle, Jaretzki, Ashley, and Berne (1968). The dilated subpleural lymphatics have not been re $-\vec{\omega}$ ported previously in this anomaly and may beo associated with poor lymphatic drainage and the $\vec{x}$ formation of the large pleural effusion.

The authors wish to thank Dr. R. D. Wilson for permission to publish this case and Drs. W. E.N Beamish and R. J. Swallow for valuable advice.

\section{REFERENCES}

Berman, E. J. (1958). Extralobar (diaphragmatic) sequestration of the lung. Arch. Surg., 76, 724.

Blesovsky, A. (1967). Pulmonary sequestration. Thorax, 22, 351 .

Gerle, R. D., Jaretzki, A., Ashley, C. A., and Berne, A. SO (1968). Congenital bronchopulmonary foregut mals formation. New Eng. J. Med., 278, 1413.

Horowitz, R. N. (1965). Extralobar sequestration of lung in newborn infant. Amer. J. Dis. Child., 110, 195.

Kissane, J. M., and Smith, M. G. (1967). Pathology of Infancy and Childhood, C. V. Mosby, St. Louis.

Köhler, R. (1969). Pulmonary sequestration. Acta radiol Diagn., 8, 337.

Nielsen, P. B. (1964). Intralobar bronchopulmonary seques? tration. Review of the literature and report of 2 cases Amer. J. Roentgenol., 92, 547.

Potter, E. L. (1961). Pathology of the Fetus and Infant 2nd ed. Year Book Medical Publishers, Chicago.

Pryce, D. M. (1946). Lower accessory pulmonary artery with intralobar sequestration of lung: a report of seven cases. J. Path. Bact., 58, 457.

Smith, R. Abbey (1956). Theory of origin of intraloba负 sequestration of lung. Thorax, 11, 10.

Spencer, H. (1962). Pathology of the Lung. Macmillan? New York.

Swierenga, J. (1959). So-called sequestration of the lung를 [In Dutch]. Ned. T. Geneesk., 103, 1166.

Wagenvoort, C. A., Heath, D., and Edwards, J. E. (1964)。 The Pathology of the Pulmonary Vasculature. Thomas Springfield, Illinois. 